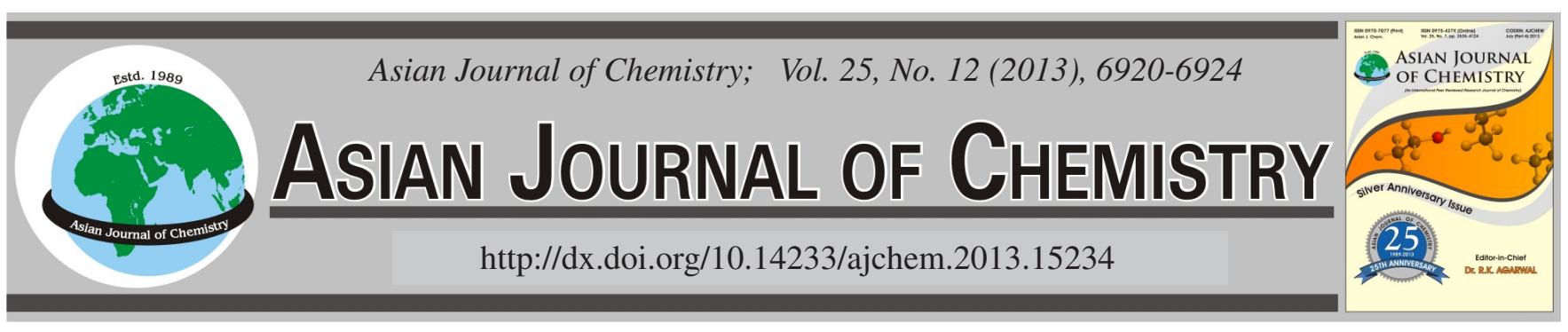

\title{
Pyrolytic Characteristics and Kinetics of Fractional Step Demineralized Coals
}

\author{
Meijun Wang, Chunhui Fu, Xiurong Ren, Liping Chang* and Kechang Xie
}

State Key Laboratory Breeding Base of Coal Science and Technology Co-founded by Shanxi Province and the Ministry of Science and Technology, Taiyuan University of Technology, Shanxi Taiyuan 030024, P.R. China

*Corresponding author: Tel/Fax: +86 351 6010482; E-mail: lpchang@tyut.edu.cn; nmgwmj1985@163.com

(Received: 29 January 2013;

Accepted: 7 June 2013)

AJC-13601

\begin{abstract}
Two Chinese coals with different reductive properties and mineral compositions were selected as the experimental samples to determine their pyrolytic characteristics. The minerals in two coals were successively leached with water, $\mathrm{HCl}$ and $\mathrm{HF}$ solutions to investigate the influence of minerals on the pyrolytic properties of the two coals. The results show that the alkali and alkaline earth metals (AAEM) minerals play an obvious catalytic role on the pyrolysis of different reductive coals, in particular, the secondary devolatilization phase. The pyrolysis process of all coal samples studied can be described by three independent first order kinetic model and the kinetic parameters of these samples during pyrolysis are affected by the minerals removed in different leaching step.

Key Words: Coal, Fractional step demineralization, Pyrolysis, Kinetics.
\end{abstract}

\section{INTRODUCTION}

The existence of inherent minerals in coal strongly depends on the geological location of the coal seam. The most common minerals in coal are quartz, clay minerals, feldspars and carbonates such as siderite, calcite and dolomite, as well as sulfide minerals such as pyrite ${ }^{1,2}$. These inherent minerals exert a substantial influence on the technological processes associated with the heat treatment of coals ${ }^{3-5}$. They may play a catalytic, restraining or inert role on the major coal utilization processes, such as hydrogenation ${ }^{6}$, gasification ${ }^{7}$, combustion $^{8}$ and pyrolysis ${ }^{4}$, depending on their content and chemical composition, which vary from coal to coal.

Weakly reductive coals are the main coal resources in Chinese western region, which are formed in inland gathering environment and subjected to a strong oxidative. These weakly reductive coals will play a vital role in the energy supply of China. Compared with the typical reductive coal, they have the characteristics of typically weak reducibility, such as low ash, sulfur and phosphorus contents but high inertinite, oxygen content, calorific value and aromatic structure9; whilst they have lower-level silicon and aluminum, higher-level alkali metals, alkaline earth metals and iron content. Based on the specific characteristic, these weakly reductive coals show a different performance in thermal conversion compared to the reductive $\mathrm{coal}^{9-11}$.

In this work, a weakly reductive coal from Shendong coal mine in the western region and a reductive coal from Pingshuo coal mine in North China were selected and investigated. This work was aimed to clarify the roles of the minerals on the pyrolysis properties of these two varieties of coals. The waterleaching, HCl-leaching and HF-leaching methods were used to remove the different types of minerals. Pyrolytic characteristics of raw coals and fractional step demineralized coals were systematically investigated using thermal gravimetric analysis, the kinetic analysis of coal pyrolysis can be determined to further reveal the effect of inherent minerals on the coal pyrolysis.

\section{EXPERIMENTAL}

Sample preparation: Two coal samples from the Pingshuo coal and Shendong coal mines were crushed, ground to the particle sizes range of $0.125-0.154 \mathrm{~mm}$ and preserved in a closed vessel away from light and oxygen. The ultimate and proximate analyses of these samples are presented in Table-1. The ash composition analyses of raw coals are presented in Table-2.

The minerals in two coals were removed using a fractional step leaching method in water, $\mathrm{HCl}$ and $\mathrm{HF}$ solutions, respectively. For water leaching process, a $10 \mathrm{~g}$ coal sample was mixed with $100 \mathrm{~mL}$ ultrapure water. The slurry was stirred for $24 \mathrm{~h}$ at room temperature, filtered and dried at $80{ }^{\circ} \mathrm{C}$ in the vacuum oven for $24 \mathrm{~h}$. For $\mathrm{HCl}$ leaching process, the $10 \mathrm{~g}$ water-leached coal was mixed with $60 \mathrm{~mL} \mathrm{HCl}$ solution (36 wt $\%, \mathrm{HCl}: \mathrm{H}_{2} \mathrm{O}=1: 1$, vol \%). The slurry was stirred for $24 \mathrm{~h}$ at room temperature, filtered, leached with ultrapure water 


\begin{tabular}{|c|c|c|c|c|c|c|c|c|}
\hline \multirow{3}{*}{ Sample } & \multicolumn{7}{|c|}{$\begin{array}{l}\text { TABLE-1 } \\
\text { PROXIMATE AND ULTIMATE ANALYSES OF COAL SAMPLES USED IN EXPERIMENT }\end{array}$} & \\
\hline & \multicolumn{3}{|c|}{ Proximate analysis (wt $\%)$} & \multicolumn{5}{|c|}{ Ultimate analysis (wt $\%$, daf) } \\
\hline & $\mathrm{M}_{\mathrm{ad}}$ & $A_{d}$ & $\mathrm{~V}_{\text {daf }}$ & $\mathrm{C}$ & $\mathrm{H}$ & $\mathrm{O}^{*}$ & $\mathrm{~N}$ & $\mathrm{~S}$ \\
\hline PSR & 2.2 & 17.9 & 37.2 & 80.4 & 5.2 & 11.9 & 1.4 & 1.1 \\
\hline PSW & 1.7 & 15.2 & 29.4 & 79.9 & 4.7 & 13.2 & 1.3 & 0.9 \\
\hline PSM & 2.0 & 12.7 & 30.7 & 81.2 & 4.8 & 11.8 & 1.3 & 0.9 \\
\hline PSD & 0.7 & 1.1 & 32.2 & 81.9 & 4.7 & 11.3 & 1.2 & 0.9 \\
\hline SDR & 9.8 & 4.5 & 33.7 & 79.8 & 4.2 & 14.6 & 0.9 & 0.5 \\
\hline SDW & 5.2 & 3.6 & 34.5 & 79.5 & 4.5 & 14.7 & 0.9 & 0.4 \\
\hline SDM & 4.4 & 2.4 & 34.5 & 78.6 & 4.3 & 15.7 & 0.8 & 0.6 \\
\hline SDD & 0.7 & 0.5 & 32.8 & 76.8 & 4.7 & 17.1 & 1.1 & 0.3 \\
\hline $\begin{array}{l}\text { Note: } \text { ad = } \\
\text { PSR = Ping } \\
\text { PSD = Ping } \\
\text { SDM = She }\end{array}$ & sis; & $\begin{array}{l}\text { is; } \mathrm{d} \\
\mathrm{V}=\mathrm{I} \\
\text { ple; }\end{array}$ & ash- & by d & & & & \\
\hline
\end{tabular}

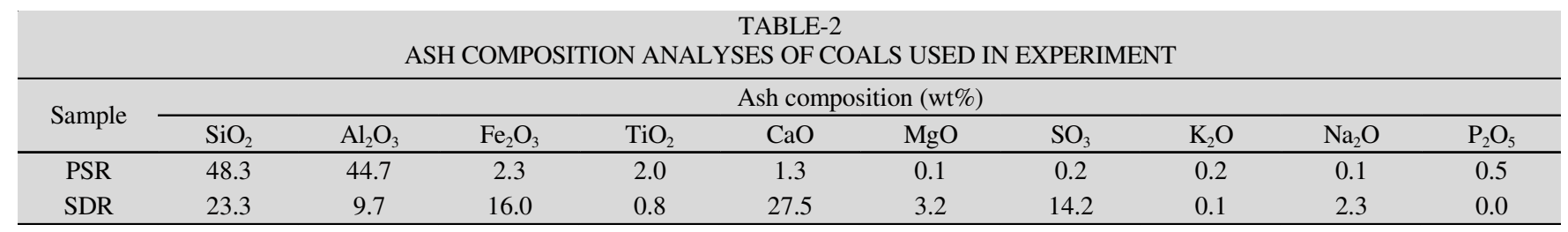

\begin{tabular}{|c|c|c|c|c|c|c|c|}
\hline \multicolumn{8}{|c|}{$\begin{array}{c}\text { TABLE-3 } \\
\text { CATION CONCENTRATIONS IN DIFFERENT LEACHING SOLUTION }\end{array}$} \\
\hline \multirow{2}{*}{ Sample } & \multirow{2}{*}{ Process } & \multicolumn{6}{|c|}{ Different cation forms $(\mu \mathrm{g} / \mathrm{L})$} \\
\hline & & $\mathrm{K}^{+}$ & $\mathrm{Na}^{+}$ & $\mathrm{Ca}^{2+}$ & $\mathrm{Mg}^{2+}$ & $\mathrm{Fe}^{3+}$ & $\mathrm{Al}^{3+}$ \\
\hline \multirow{3}{*}{ Pingshuo coal } & Water-leaching & 0.08 & 0.09 & 0.452 & 0.14 & $<0.0001$ & 0.32 \\
\hline & HCl-leaching & 2.86 & 1.54 & 16.42 & 2.16 & 4.56 & 62.30 \\
\hline & HF-leaching & 0.43 & 0.35 & 6.11 & 0.28 & 12.89 & 238.11 \\
\hline \multirow{3}{*}{ Shendong coal } & Water-leaching & 0.19 & 1.21 & 1.712 & 1.95 & $<0.0001$ & 0.32 \\
\hline & HCl-leaching & 0.39 & 17.58 & 141.00 & 17.06 & 14.11 & 34.47 \\
\hline & HF-leaching & 0.42 & 27.81 & 162.71 & 40.67 & 21.21 & 108.56 \\
\hline
\end{tabular}

until no chloride ion was detected and dried at $80{ }^{\circ} \mathrm{C}$ in a vacuum oven for $24 \mathrm{~h}$. For HF leaching process, the $10 \mathrm{~g} \mathrm{HCl}-$ leached coal was mixed with $75 \mathrm{~mL} \mathrm{HF}(40 \%)$. The slurry was stirred for $24 \mathrm{~h}$ at room temperature, filtered, leached with ultrapure water and dried at $80^{\circ} \mathrm{C}$ in the vacuum oven for 24 h. The raw coal sample was denoted as $\mathrm{R}$, the water-leached sample was denoted as $\mathrm{W}$, the $\mathrm{HCl}$-leached sample was denoted as $\mathrm{M}$ and the HF-leached sample was denoted as D.

The filtrate with different solvents from the fractional step washing coal process were metered volume to $500 \mathrm{~mL}$ of volumetric flask, the $\mathrm{K}^{+}, \mathrm{Na}^{+}, \mathrm{Ca}^{2+}, \mathrm{Mg}^{2+}, \mathrm{Fe}^{3+}$ and $\mathrm{Al}^{3+}$ concentrations were detected by atomic absorption spectrometer (Varian, U.S.). The results of the analysis were presented in Table-3.

Apparatus and procedure: An STA 409C TGA apparatus (Netzsch, Germany) was used. Approximately $20 \mathrm{mg}$ sample was placed on the platinum pan, which was suspended from a thin quartz rod attached to one arm of the microbalance. The system was purged with high purity nitrogen prior to the heating of sample from room temperature to $1000{ }^{\circ} \mathrm{C}$ at a constant heating rate of $10^{\circ} \mathrm{C} / \mathrm{min}$. The carrier gas was $\mathrm{N}_{2}$, with a flow rate of $60 \mathrm{~mL} / \mathrm{min}$.

\section{RESULTS AND DISCUSSION}

Effects of pyrolysis characterization on the fractional step demineralization: The TG and DTG curves of Pingshuo coal and Shendong coal raw coals and their demineralized samples during pyrolysis are illustrated in Fig. 1. It can be seen that the weight losses of the samples gradually increase with increasing temperature, but the change trend between raw coal and the samples leached by different solution for the same coal is different and there also exists difference between Pingshuo coal and Shendong coal. We can see easily that the weight losses of PSR and PSW are obviously higher than that of PSM and PSD, which indicates that the removing minerals by $\mathrm{HCl}$ leaching have the catalytic role on the pyrolysis for Pingshuo coal. Meanwhile, the TG curves of PSM and PSD are almost identical, which suggests that the retaining minerals after $\mathrm{HCl}$ leaching almost have no effect on the pyrolysis reactivity of Pingshuo coal. In order to investigate which mineral can be effectively removed by different leaching processes respectively and further review which mineral has the catalytic role on the pyrolysis, the AAS analysis was used to measure the metal cations in the leaching solution and the results can be seen in Table-3. The results show that the majority of alkali and alkaline earth metals (AAEM) minerals can be removed by the $\mathrm{HCl}$ leaching process, which indicates that these alkali and alkaline earth metals minerals play a catalytic role on the pyrolysis for Pingshuo coal. For Shendong coal, the weight loss of SDD is evidently lower than that of other three coals for Shendong coal. It reveals that the retaining 

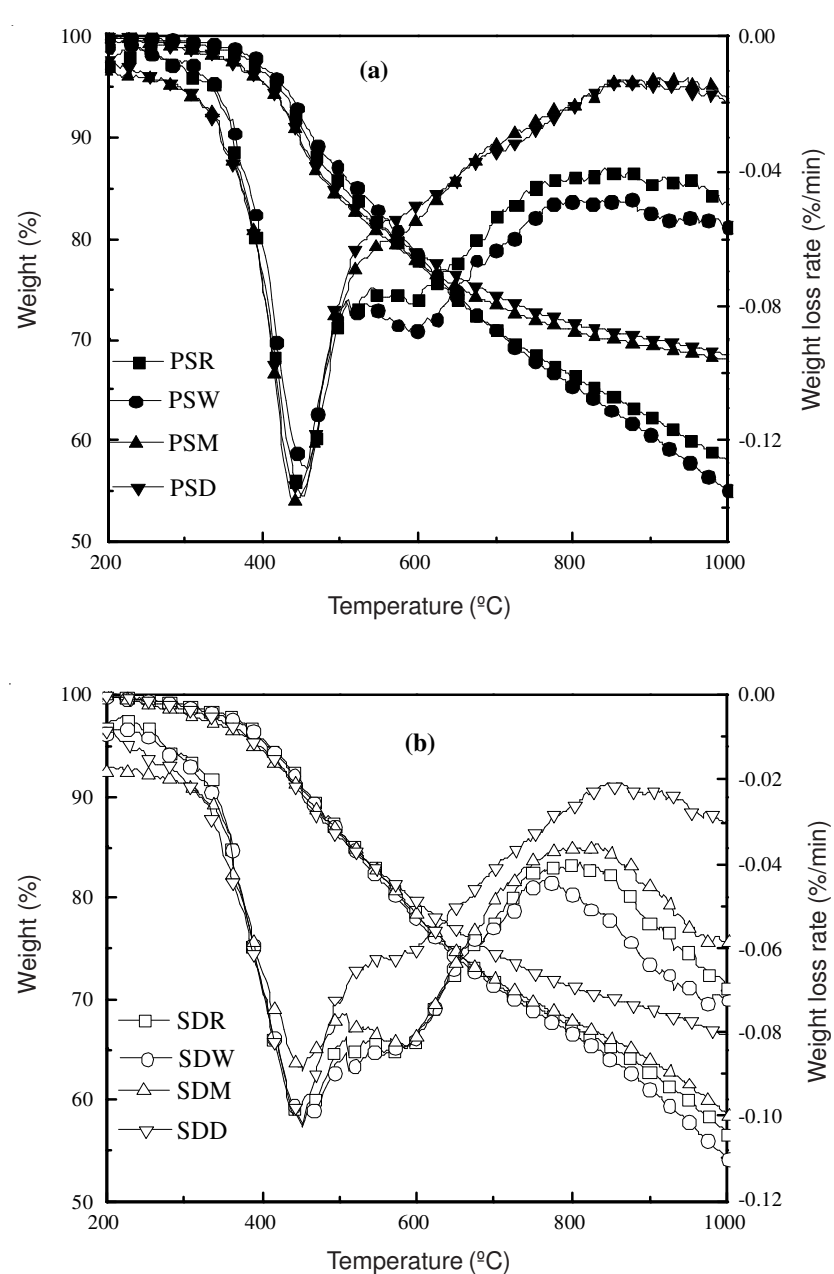

Fig. 1. TG and DTG curves of Pingshuo coal and Shendong coal during pyrolysis in $\mathrm{N}_{2}$ atmosphere

minerals in SDM after $\mathrm{HCl}$ leaching have catalytic role on the pyrolysis of Shendong coal, which is different from Pingshuo coal. From Table-3, we can see that most of alkali and alkaline earth metals minerals can be removed by HF leaching process, in addition to Al-containing minerals. Compare with the Pingshuo coal, the most of Al-containing minerals can be removed by HF leaching process, but have no effect on the pyrolysis reactivity of Pingshuo coal. Therefore, we can infer that the Al-containing minerals have an inert role on the pyrolysis. In other words, only the alkali and alkaline earth metals minerals have a catalytic role on the pyrolysis of two coals, which is consistent with the published work ${ }^{3,4}$. As mentioned above, Shendong coal, as the weakly reductive coal, has some specific properties compare with Pingshuo coal. Table-2 showed it shows that lower-level silicon and aluminum, higher-level alkali metals, alkaline earth metals and iron contents are found in SDR. Generally, minerals in coal exist in two forms of included and excluded forms. Some minerals including alkali metals or alkaline earth metals exist in coal in the included form, as the primary and secondary mineral. They closely link with the organic matrix in coal and are embedded in the coal fabric. May be those catalytic minerals cannot fully removed by $\mathrm{HCl}$ leaching process for Shendong coal.

Based on the DTG curves from Fig. 1, we can see that there is a similar weight loss peak in the $350-500{ }^{\circ} \mathrm{C}$ temperature range, which is the primary devolatilization phase. These peaks are identical for the raw coal and the samples leached from Pingshuo coal and Shendong coal, respectively. From ca. 500 to $1000{ }^{\circ} \mathrm{C}$, as the secondary devolatilization phase, the peak shapes and weight loss amounts vary with the pre-treatment of samples. PSR and PSW exhibit obvious weight losses at ca. $600{ }^{\circ} \mathrm{C}$, but no observable peak is shown for PSM and $\mathrm{PSD}$ at this temperature range. For the Shendong coal, samples exhibit obvious weight loss peaks at $c a .600{ }^{\circ} \mathrm{C}$, except for SDD. The weight loss between 200 and $350^{\circ} \mathrm{C}$, mainly from the volatilization of the mobile phase and the thermal decomposition of weak bonds, is small, which is in the range of 1.0$3.1 \mathrm{wt} \%$. Weight loss mainly takes place in the temperature range between 350 and $500{ }^{\circ} \mathrm{C}$, attributed to the primary devolatilization phase. In this phase, the weight loss of Pingshuo coals is within 12.3-13.9 wt \%, while 10.6-11.7 wt $\%$ for Shendong coals. It is clear that the weight loss in this phase have no obvious difference for different leaching process samples from Pingshuo coal and Shendong coal. Thus, it indicates that those alkali and alkaline earth metals minerals have no effect on the pyrolysis activity in this phase. The proportion of weight loss between 500 and $1000{ }^{\circ} \mathrm{C}$ varies with the different leached samples from Pingshuo coal and Shendong coal. There is an evident change of weight loss for Pingshuo coal before and after $\mathrm{HCl}$ leaching process, the weight loss is decreased from $31.6 \mathrm{wt} \%$ for PSW to $16.0 \mathrm{wt} \%$ for PSM, it also indicates that those alkali and alkaline earth metals minerals removed by $\mathrm{HCl}$ leaching have catalytic role on the pyrolysis activity in this phase. For the Shendong coal, there is an obvious decrease from $27.7 \mathrm{wt} \%$ for SDM down to $19.6 \mathrm{wt} \%$ for SDD. This makes clearly that those alkali and alkaline earth metals minerals removed by HF leaching have catalytic role on the pyrolysis activity for Shendong coal, which is inconsistent with Pingshuo coal. For the water leaching process, the weight loss is increased after water leaching for two coals. Table- 3 showed that there is only a few metal cations exist in the water leaching solution. A small amount of watersoluble carbonates, sulfates, chlorides, physically absorbed inorganics ${ }^{12}$ or dust can be removed by water leaching process, which plays a role in cleaning the surface of coal. It should be a reason why the weight loss increases after water leaching for two coals.

Kinetics analysis of coal pyrolysis: The kinetic analysis has been studied to further reveal the effect of fractional step demineralization on the coal pyrolysis. It was assumed that coal pyrolysis is a first order reaction ${ }^{13}$ and then the kinetic parameters of coal pyrolysis were determined by the integral method $^{4}$. So the coal pyrolysis reaction equation may simply be expressed as following formula:

$$
\frac{\mathrm{dx}}{\mathrm{dt}}=\mathrm{A} \exp \left(-\frac{\mathrm{E}}{\mathrm{RT}}\right)(1-\mathrm{x})
$$

where $\mathrm{A}$ is pre-exponential factor, $\mathrm{E}$ is activation energy, $\mathrm{T}$ is temperature, $\mathrm{t}$ is time, $\mathrm{x}$ is pyrolysis conversion which can be calculated by:

$$
\mathrm{x}=\frac{\left(\mathrm{W}_{\mathrm{o}}-\mathrm{W}_{\mathrm{t}}\right)}{\left(\mathrm{W}_{\mathrm{o}}-\mathrm{W}_{\mathrm{f}}\right)}
$$


where $\mathrm{W}_{\mathrm{o}}$ is the original mass of the test sample; $\mathrm{W}_{\mathrm{t}}$ is the mass at time $t$ and $\mathrm{W}_{\mathrm{f}}$ is final mass at the end of pyrolysis.

For a constant heating rate $\mathrm{H}$ during pyrolysis, $\mathrm{H}=\mathrm{dt} / \mathrm{dt}$, rearranging Eq. (1) and integrating gives

$$
\ln \left[\frac{-\ln (1-\mathrm{x})}{\mathrm{T}^{2}}\right]=\ln \left[\frac{\mathrm{AR}}{\mathrm{HE}}\left(1-\frac{2 \mathrm{RT}}{\mathrm{E}}\right)\right]-\frac{\mathrm{E}}{\mathrm{RT}}
$$

Since it may be shown that for most values of $\mathrm{E}$ and for the temperature range of the pyrolysis, the expression $\ln [\mathrm{AR} /$ $\mathrm{HE}(1-2 \mathrm{RT} / \mathrm{E})]$ in eqn. 3 is essentially constant, if the left side of eqn. 3 is plotted $v s .1 / \mathrm{T}$, a straight line may be obtained if the process can be assumed as a frist-order reaction. Based on the slope and intercept of the straight line, the activation energy $\mathrm{E}$ and the pre-exponential factor A can also be determined ${ }^{4}$.

The plots of $\ln \left[-\ln (1-\mathrm{x}) / \mathrm{T}^{2}\right]$ versus $1 / \mathrm{T}$ is shown in Fig. 2, it can be seen that the reaction of coal pyrolysis should be described by three independent first order reaction at different temperature regions. The kinetic parameters and weight loss of coal samples at different stages is shown in Table-4, we can see that there are good correlation coefficient for all lines, which indicates that three independent first order reaction model fits the experimental data very well. From Table-4, it can be seen that the fractional step demineralized coals have different activation energy and pre-exponential factor with two raw coals. We can see that PSR and PSW have almost equivalent activation energy. After $\mathrm{HCl}$ leaching, the activation energy of PSM is obvious increased, that of PSD has almost unchanged compared with the PSM. For Shendong coal, the activation energy of fractional step demineralized coals is also higher than that of SDR. Normally, high activation energy means that the

\begin{tabular}{|c|c|c|c|c|c|}
\hline \multicolumn{6}{|c|}{$\begin{array}{c}\text { TABLE-4 } \\
\text { KINETICS PARAMETERS OF PINGSHUO COAL } \\
\text { AND SHENDONG COAL PYROLYSIS }\end{array}$} \\
\hline Sample & $\begin{array}{l}\text { Temp. } \\
\left({ }^{\circ} \mathrm{C}\right)\end{array}$ & $\begin{array}{c}\Delta \mathrm{m}(\mathrm{wt} \%, \\
\text { daf) }\end{array}$ & $\begin{array}{c}\mathrm{E} \\
(\mathrm{KJ} / \mathrm{mol})\end{array}$ & $\underset{\left(\min ^{-1}\right)}{\mathrm{A}}$ & $-\mathrm{R}^{\mathrm{a}}$ \\
\hline \multirow{3}{*}{ PSR } & $282-377$ & 1.54 & 27.0 & 2.16 & 0.994 \\
\hline & $377-469$ & 9.82 & 63.4 & 2708.06 & 0.998 \\
\hline & $469-899$ & 25.91 & 13.3 & 4.18 & 0.965 \\
\hline \multirow{3}{*}{ PSW } & $283-371$ & 1.17 & 31.6 & 5.23 & 0.989 \\
\hline & $371-472$ & 9.53 & 63.4 & 2657.19 & 0.997 \\
\hline & $472-899$ & 28.38 & 13.0 & 16.04 & 0.968 \\
\hline \multirow{3}{*}{ PSM } & $280-372$ & 2.05 & 37.3 & 7.64 & 0.998 \\
\hline & $372-473$ & 10.53 & 70.4 & 5773.60 & 0.995 \\
\hline & $473-898$ & 17.15 & 17.4 & 1.22 & 0.975 \\
\hline \multirow{3}{*}{ PSD } & $278-375$ & 2.40 & 40.9 & 12.29 & 0.997 \\
\hline & $375-470$ & 9.75 & 73.0 & 7542.64 & 0.997 \\
\hline & $470-898$ & 17.02 & 19.8 & 1.18 & 0.973 \\
\hline \multirow{3}{*}{ SDR } & $266-371$ & 2.03 & 21.4 & 0.97 & 0.997 \\
\hline & $371-469$ & 8.27 & 36.1 & 14.24 & 0.999 \\
\hline & 469-899 & 26.34 & 14.3 & 1.13 & 0.979 \\
\hline \multirow{3}{*}{ SDW } & $266-371$ & 2.15 & 30.4 & 4.95 & 0.999 \\
\hline & $371-469$ & 5.04 & 44.3 & 79.19 & 0.997 \\
\hline & $469-899$ & 31.05 & 13.6 & 1.44 & 0.953 \\
\hline \multirow{3}{*}{ SDM } & $266-371$ & 2.59 & 35.1 & 7.07 & 0.999 \\
\hline & $371-472$ & 7.65 & 50.1 & 151.06 & 0.999 \\
\hline & $472-899$ & 24.55 & 14.8 & 5.26 & 0.977 \\
\hline \multirow{3}{*}{ SDD } & $282-371$ & 2.45 & 31.2 & 3.45 & 0.999 \\
\hline & $371-472$ & 8.24 & 48.3 & 106.26 & 0.999 \\
\hline & $472-897$ & 19.23 & 18.0 & 1.11 & 0.991 \\
\hline
\end{tabular}

$\mathrm{R}$, correlation coefficient.
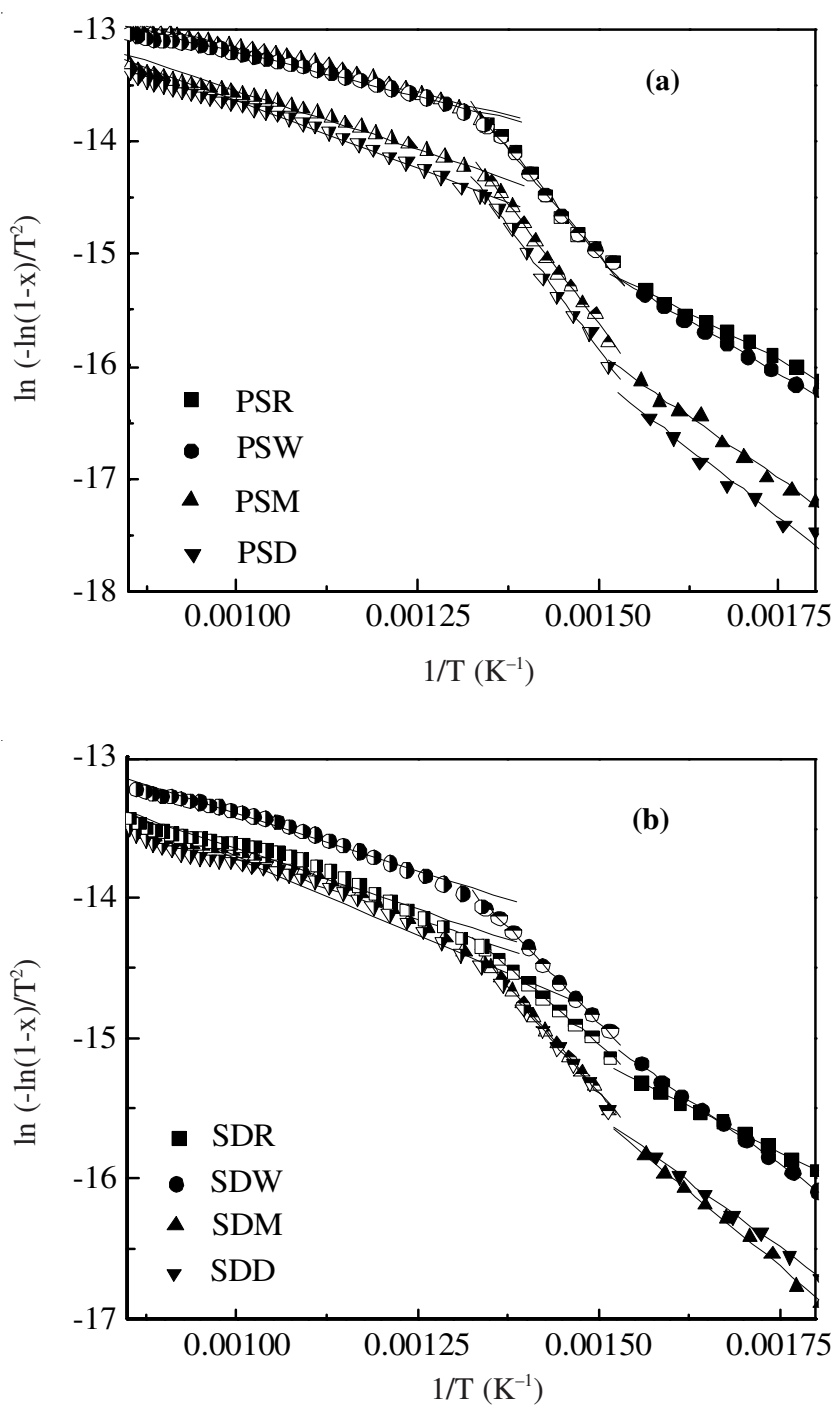

Fig. 2. Plots of $\ln \left(-\ln (1-\mathrm{x}) / \mathrm{T}^{2}\right)$ vs. $1 / \mathrm{T}$ of $\mathrm{PS}$ and SD coals pyrolysis calculated by one-step integral method

reaction needs more energy from the surroundings. Thus, the increasing of activation energy of the fractional step demineralized coals also proves that those inherent minerals removed by the demineralization have the catalytic characteristics on the pyrolysis. It is consistent with the above analysis, the catalytic role of the alkali and alkaline earth metals minerals on the coal pyrolysis.

\section{Conclusion}

Based on the above analysis and discussion, the following conclusions can be drawn:

(1) Inherent minerals can be successful removed by the fractional step demineralization, most of alkali and alkaline earth metals minerals in Pingshuo coal were removed by the $\mathrm{HCl}$ leaching, only $\mathrm{HF}$ leaching can remove the Al-containing minerals, which is different form Shendong coal.

(2) The removed alkali and alkaline earth metals minerals in coal play a catalytic role on pyrolysis characteristics, which mainly present in the secondary devolatilization phase.

(3) The change of activation energy of the fractional step demineralized coals also proves the catalytic role of removed inherent minerals on the pyrolysis of two coals. 


\section{ACKNOWLEDGEMENTS}

The authors gratefully acknowledged the financial supports of National Natural Science Foundation of China (21176165, U1261110), Specialized Research Fund for the Doctoral Program of Higher Education (20111402110009) and Shanxi Province Basic Conditions Platform for Science and Technology Project (2012091018).

\section{REFERENCES}

1. C.R. Ward, Int. J. Coal Geol., 50, 135 (2002)

2. I.C. Lópeza and C.R. Ward, Int. J. Coal Geol., 73, 3 (2008)

3. N.A. Oztas and Y. Yurum, Fuel, 79, 1221 (2000).

4. Q.R. Liu, H.Q. Hu, Q. Zhou, S.W. Zhu and G.H. Chen, Fuel, 83, 713 (2004).
5. T. Ahmad, I.A. Awan, J. Misar and I. Ahmad, Energ. Convers. Manage., 50, 1163 (2009).

6. V.I. Sharypov, B.N. Kuznetsov, N.G. Beregovtsova, O.L. Reshetnikov and S.V. Baryshnikov, Fuel, 75, 39 (1996).

7. J. Bai, W. Li, C.Z. Li, Z.Q. Bai and B.Q. Li, Fuel Process. Technol, 91, 404 (2010)

8. L.B. Mendez, A.G. Borrego, M.R. Martinez-Tarazona and R. Menendez, Fuel, 82, 1875 (2003).

9. Y.P. Zhao, H.Q. Hu, L.J. Jin, B. Wu and S.W. Zhu, Energy Fuel, 23, 870 (2009).

10. J.H. Wang, F. Li, L.P. Chang and K.C. Xie, Energy Sources, Part A: Recovery, Utilization and Environmental Effects, 32, 1869 (2010).

11. J.H. Wang, F. Li, L.P. Chang and K.C. Xie, Energy sources, Part A: Recovery, Utilization and Environmental Effects, 33, 529 (2010).

12. M. Telfer and D.K. Zhang, Fuel, 80, 2085 (2001).

13. Y.G. Pan, E. Velo and L. Puigjaner, Fuel, 75, 412 (1996). 